\title{
Trauma-induced coagulopathy: impact of the early coagulation support protocol on blood product consumption, mortality and costs
}

\author{
Giuseppe Nardi ${ }^{1 *}$, Vanessa Agostini ${ }^{2}$, Beatrice Rondinelli ${ }^{3}$, Emanuele Russo ${ }^{4}$, Barbara Bastianini ${ }^{1}$, Giovanni Bini ${ }^{4}$, \\ Simona Bulgarelli ${ }^{2}$, Emiliano Cingolani ${ }^{1}$, Alessia Donato ${ }^{5}$, Giorgio Gambale ${ }^{4}$ and Giulia Ranaldi ${ }^{1}$
}

\begin{abstract}
Introduction: Hemorrhage is the principal cause of death in the first few hours following severe injury. Coagulopathy is a frequent complication of critical bleeding. A network of Italian trauma centers recently developed a protocol to prevent and treat trauma-induced coagulopathy. A pre-post cohort multicenter study was conducted to assess the impact of the early coagulation support (ECS) protocol on blood products consumption, mortality and treatment costs.

Methods: We prospectively collected data from all severely injured patients (Injury Severity Score (ISS) >15) admitted to two trauma centers in 2013 and compared these findings with the data for 2011. Patients transfused with at least 3 units of packed red blood cells (PRBCs) within 24 hours of an accident were included in the study. In 2011, patients with significant hemorrhaging were treated with early administration of plasma with the aim of achieving a high $(\geq 1: 2)$ plasma-to-PRBC ratio. In 2013, the ECS protocol was the treatment strategy. Outcome data, blood product consumption and treatment costs were compared between the two periods.

Results: The two groups were well matched for demographics, injury severity (ISS: 32.9 in 2011 versus 33.6 in 2013) and clinical and laboratory data on admission. In 2013, a 40\% overall reduction in PRBCs was observed, together with a $65 \%$ reduction in plasma and a $52 \%$ reduction in platelets. Patients in the ECS group received fewer blood products: 6.51 units of PRBCs versus 8.14 units. Plasma transfusions decreased from 8.98 units to 4.21 units $(P<0.05)$, and platelets fell from 4.14 units to 2.53 units $(P<0.05)$. Mortality in 2013 was 13.5\% versus 20\% in 2011 (13 versus 26 hospital deaths, respectively) (nonsignificant). When costs for blood components, factors and point-of-care tests were compared, a $€ 76,340$ saving in 2013 versus 2011 (23\%) was recorded.
\end{abstract}

Conclusions: The introduction of the ECS protocol in two Italian trauma centers was associated with a marked reduction in blood product consumption, reaching statistical significance for plasma and platelets, and with a nonsignificant trend toward a reduction in early and 28-day mortality. The overall costs for transfusion and coagulation support (including point-of-care tests) decreased by 23\% between 2011 and 2013.

\section{Introduction}

Hemorrhage is the principal cause of death in the first few hours following severe injury. Coagulopathy is a frequent complication of hemorrhage and may occur in up to $25 \%$ of patients, even before hospital admission [1]. Recently, a multidisciplinary, pan-European group of experts launched the Stop the Bleeding Campaign [2], a campaign to counteract preventable deaths from uncontrolled

\footnotetext{
* Correspondence: gnardi@scamilloforlanini.rm.it

'Department of Shock and Trauma Center, S Camillo-Forlanini Hospital,

Circonvallazione Gianicolense 87, Roma 00152, Italy

Full list of author information is available at the end of the article
}

bleeding following traumatic injury. The goal of the campaign is to reduce the number of patients who die within 24 hours after hospital admission (due to exsanguination) by a minimum of $20 \%$. This goal was set in response to the updated European guidelines for management of bleeding and coagulopathy [3]. These guidelines recommend that every trauma facility implement an evidencebased treatment algorithm for the bleeding trauma patient and promote the use of treatment algorithms to guide clinical management.

The Italian Trauma Centers Network (TUN) responded to the recommendations by developing a treatment 


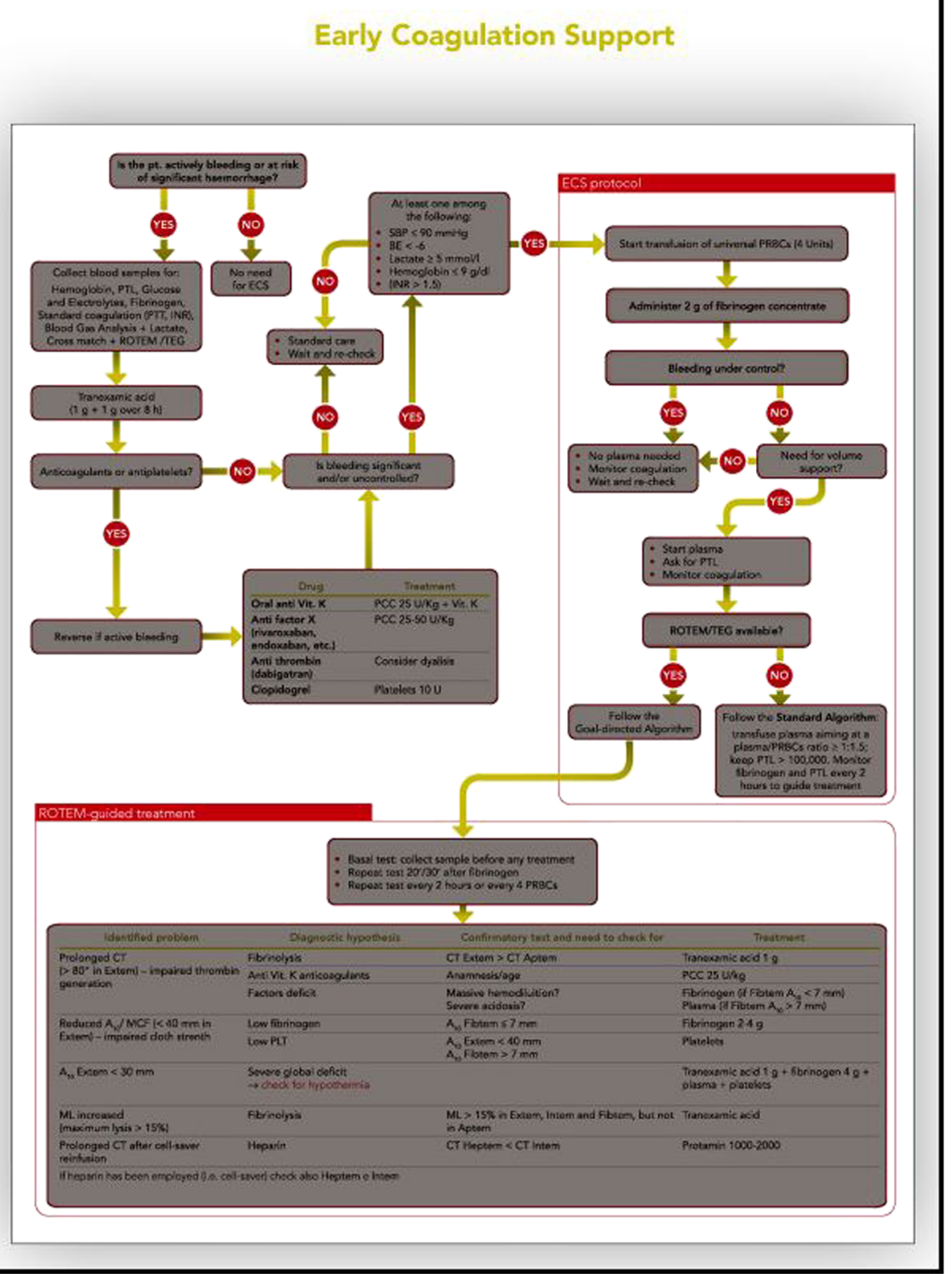

Figure 1 The early coagulation support (ECS) protocol.

algorithm (early coagulation support (ECS)). The ECS protocol (Figure 1) has been described in detail elsewhere [4]. It is an integrated part of a comprehensive damage resuscitation strategy. It is also based on fluid restriction and the prohibition of colloids. The ECS strategy has been formally adopted by several Italian trauma centers. To our knowledge, this is the first example in Europe of the adoption of the same step-by-step algorithm for the management of trauma-induced coagulopathy by a large number of trauma centers. The centers that cooperated in the development of the protocol jointly decided to monitor the impact of ECS on consumption of blood products, trauma mortality and morbidity, and financial costs. A multicenter prospective cohort study with retrospective control was therefore planned by the TUN steering committee.

We report the preliminary results of the ongoing study, based on first-year data from the first two trauma centers that implemented ECS.

\section{Material and methods}

Our study was planned as a multicenter prospective cohort study with a retrospective control. According to the 
original study design, the TUN-associated institutions were required to join the study at the same time. However, the process of adopting the ECS protocol took significant and varying amounts of time from hospital to hospital. On 1 January 2013, only two of the trauma centers were ready to start the study.

We present the results of the first year of use of ECS at the first two sites that adopted the protocol: S Camillo Hospital in Rome and Bufalini Hospital, Cesena, Italy. Both hospitals are high-volume level I trauma centers that serve a population of about 2 million each. Data from the post-ECS adoption period (1 January 2013 to 31 December 2013) and the pre-adoption period (1 January 2011 to 31 December 2011) were compared. In the pre-adoption period, patients were treated according to the 2010 European guidelines [5]. Patients with critical bleeding received plasma as early as possible in a plasma-to-packed red blood cells (PRBCs) ratio aimed at 1:1. Plasma was thawed soon after the patient was admitted, although in a limited number of cases the thawing process could be anticipated based on the prehospital team alert. If required, platelets (PTL) were administered with the aim of maintaining the PTL count $\geq 100,000$, as recommended by the guidelines. Coagulation was monitored mainly by means of the traditional laboratory tests (international normalized ratio, prothrombin time, activated partial thromboplastin time, fibrinogen by Clauss method), as point-of-care (POC) tests were not available. The main characteristics of the two different treatment and monitoring strategies are shown in Table 1.

In 2013, patients were treated according to the ECS algorithm. In both institutions, POC rotational thromboelastometry (ROTEM) was systematically used to monitor coagulation. However, although a blood samples for POC were collected on admission, the initial treatment was based only on clinical signs and on the results of the initial blood gas analysis. Therefore, patients with signs of severe hypoperfusion received the initial coagulation support even before the results of the first (basal)
ROTEM test. According to the ECS protocol, patients who met one or more of the following criteria ("clinical" criteria) received a standard dose of fibrinogen concentrate $(2 \mathrm{~g})$, together with the first units of universal blood: systolic blood pressure (SBP) $<100 \mathrm{mmHg}$, lactate $\geq 5 \mathrm{mmol} / \mathrm{L}$, base excess $(\mathrm{BE}) \leq 6$ or hemoglobin $\leq 9 \mathrm{~g} / \mathrm{dl}$. POC tests (ROTEM delta; Tem International, Munich, Germany) were subsequently used systematically to monitor coagulation and guide the treatment algorithm. Plasma was not administered in the early treatment stage. Permissive hypotension and moderate fluid restriction were recommended until surgical bleeding control was achieved. However, in cases of prolonged bleeding, if an increasing number of PRBCs was required and high volume support was needed, plasma was transfused for volume and coagulation support. In both study periods, patients were resuscitated according to a damage control resuscitation strategy [6] with the aim of limiting the amount of fluids before surgery. However, whereas in 2011 colloids were allowed, the ECS protocol used in 2013 recommended not to use them. During both time periods, the administration of tranexamic acid soon after admission was a mandatory part of treatment [7].

For the purpose of this study, we chose to use for the control group the data of 2011 rather than those of 2012 to allow a 12-month gap between strategies. This ensured that protocols would not overlap and results would not be skewed.

At both hospitals, data for all severely injured patients (Injury Severity Score (ISS) >15) admitted to the intensive care unit (ICU) and those who die before they can be admitted are entered into the trauma center's database. Trauma patients transfused with at least $3 \mathrm{U}$ of PRBC within 24 hours of a traumatic injury were identified via blood banks' electronic registries as study candidates. Data from the ICU and emergency room electronic records were matched with the blood bank registries to confirm the blood units transfused within the study's time spans. For patients transferred from other hospitals, transfusion data before referral and/or during transport were

Table 1 Main characteristics of the two treatment strategies ${ }^{a}$

\begin{tabular}{lll}
\hline Treatment strategies & Standard treatment (2011) & Early coagulation support (2013) \\
\hline Fluid resuscitation & Crystalloids and colloids & Crystalloids only \\
Fluid treatment strategy & $\begin{array}{l}\text { Permissive hypotension, relative fluid restriction } \\
\text { (except in TBI patients) }\end{array}$ & $\begin{array}{l}\text { Permissive hypotension, relative fluid restriction } \\
\text { (except in TBI patients) }\end{array}$ \\
$\begin{array}{ll}\text { Tranexamic acid } \\
\text { Initial coagulation support }\end{array}$ & "Initial" plasma at high level $(>1: 2)$ plasma:PRBC ratio & Fibrinogen $2 \mathrm{~g}$ \\
Treatment of uncontrolled bleeding & Plasma:PRBC ratio ( $>1: 2)$ Keep PTL $>100,000$ & Goal-directed treatment \\
& & (including plasma:PRBC $>1: 2$ if indicated) \\
Coagulation monitoring & Traditional: INR, aPTT, PTL, fibrinogen (von Clauss method) & Viscoelastic POC
\end{tabular}

aPTT, Activated partial thromboplastin time; INR, International normalized ratio; POC, Point of care; PRBC, Packed red blood cells; PTL, Platelets; TBI, Traumatic brain injury. 
also collected and verified by the blood banks. Information about all patients who met the study criteria were entered into a multicenter database.

\section{Inclusion criteria}

All severely injured patients admitted directly to the trauma centers or transferred by another institution within 6 hours of an accident were candidates for inclusion if they met the following criteria: ISS $>15$; received at least $3 \mathrm{U}$ of PRBC within the first 24 hours following the accident; either admitted to the ICU or died after hospital admission but before ICU admission, either in the emergency department or in the operating room (OR).

\section{Exclusion criteria}

Patients who had a cardiac arrest prior to admission (or who died en route to the hospital) were excluded. Patients transferred more than 6 hours after an accident or with incomplete medical reports were also excluded.

\section{Definitions}

To allow homogeneous collection of transfusion data, standard definitions of blood components were used. Each unit of PRBC has an average volume of $250(+10 \%)$ $\mathrm{ml}$ and a hematocrit of $50 \%$ to $60 \%$. The amount of blood obtained through recovery techniques and reinfused was computed considering each $250 \mathrm{ml}$ of blood reinfused equivalent to $1 \mathrm{U}$ of PRBC. Plasma is available either as $200 \mathrm{ml} / \mathrm{U}$ of pathogen-inactivated plasma (PlasmaSafe; Kedrion, Barga, Italy) or as single-donor apheresis plasma $(600 \mathrm{ml} / \mathrm{U})$. For the purposes of this study, $200 \mathrm{ml}$ of plasma are considered equal to $1 \mathrm{U}$. PTL are available either as single-donor apheresis or as multiple-donor packs. For the purpose of this study, a single-donor pack is considered equal to six multipledonor packs. Fibrinogen (Haemocomplettan; CSL-Behring, Marburg, Germany) is available as a 1-g lyophilized, purified human concentrate. Fibrinogen concentrate is not available on the market in Italy, and hospitals are supplied with limited amounts on the basis of authorization from the Italian Medicines Agency at a fixed price of $€ 400 / 1 \mathrm{~g}$. Industrial plasma costs on average $€ 75 / 200 \mathrm{ml}$. There is no established commercial price for PRBC and PTL. However, a reference cost is based on current published figures [8,9]: $€ 186$ for $1 \mathrm{U}$ of PRBC and $€ 115$ for $1 \mathrm{U}$ of PTL concentrate.

All causes of death were included. Mortality within the first 24 hours was mainly due to hemorrhage. Patients meeting the inclusion criteria who subsequently developed brain death were considered dead after 24 hours if the organ harvesting took place more than 24 hours after the accident in a heart-beating donor.

\section{Statistical analysis}

Distribution of the data was tested with the KolmogorovSmirnov test. Data are presented as mean with standard deviation or median with interquartile range, depending on the underlying distribution. Continuous variables were compared using the Mann-Whitney $U$ test or Student's $t$-test, depending on the underlying distribution. For categorical variables, the $X^{2}$ test was used. A $P$-value $<0.05$ was considered significant.

The study was approved by the Ethics Committee Lazio 1 as a prospective observational study with a retrospective control. It was determined to waive patients' consent because in 2013 the ECS protocol was the standard of care in the two institutions, after being formally approved by the directors of both hospitals.

\section{Results}

A substantially equal number of severely injured patients were admitted to the two trauma centers in 2011 and 2013 (435 and 431, respectively). However, 30\% fewer patients required transfusion of $\geq 3 \mathrm{U}$ of PRBCs during the first 24 hours in $2013(n=96)$ than in $2011(n=130)$. Patients in the two periods were well matched in terms of demographics, physiologic parameters on admission, anatomic severity index and laboratory data (Table 2). Seventy percent of the patients in both groups were taken directly from the accident to the trauma center, with an average admission time of 69 minutes ( \pm 20 minutes). In 2011, patients received an average of 8.14 U of PRBCs versus $6.51 \mathrm{U}$ in 2013 (nonsignificant), with an overall decrease in blood consumption from 1,048 U to $625 \mathrm{U}$ $(-40 \%)$ (Table 3$)$. In 2011, 33 patients required massive transfusions (MTs), defined as $\geq 10 \mathrm{U}$ of $\mathrm{PRBC}$ ) versus 16 in 2013. The average number of PRBC transfused into the MT patients was $17.8 \mathrm{U}$ in 2011 versus $14.9 \mathrm{U}$ in 2013. The average amount of plasma transfused to the patients in the study groups was reduced from $8.98 \mathrm{U}$ to $4.21 \mathrm{U}(P<0.05)$, for an overall $65 \%$ reduction from 1,167 $\mathrm{U}$ to $405 \mathrm{U}$. The plasma-to-PRBC ratio decreased in 2013 if compared with 2011 for each amount of PRBC transfused (Table 4). The average amount of PTL transfused was reduced from $4.14 \mathrm{U}$ to $2.53 \mathrm{U}(P<0.05)$, an overall $52 \%$ reduction in PTL consumption from $538 \mathrm{U}$ to $258 \mathrm{U}$. In 2013, $134 \mathrm{~g}$ of fibrinogen concentrate were used by the two hospitals. Fibrinogen was not used in 2011.

In 2011, 26 (20\%) of 130 patients died within 28 days following their accidents, and 8 of them died as a result of exsanguination in the first 24 hours. In the 2013 group, 13 (13.5\%) of 96 patients died within 28 days, and 3 patients died within the first 24 hours. The difference in mortality between the two periods was not statistically significant. Of the 49 MT patients, 14 died: 10 (30\%) of 33 in 2011 and 4 (25\%) of 16 in 2013. 
Table 2 Patient characteristics ${ }^{\mathrm{a}}$

\begin{tabular}{|c|c|c|c|c|c|c|}
\hline & & & 2011 & 2013 & Missing & $P$-value \\
\hline \multicolumn{3}{|l|}{ Patients with ISS $>15$ and $\geq 3 \cup$ of PRBC } & 130 & 96 & & \\
\hline Age, yr & \multicolumn{2}{|c|}{ Mean (SD) } & $48.8( \pm 19.6)$ & $51.1( \pm 21.6)$ & - & 0.436 \\
\hline \multirow[t]{2}{*}{ Sex } & n (\%) & M & $95(73.1 \%)$ & $65(67.7 \%)$ & - & 0.459 \\
\hline & & $\mathrm{F}$ & $35(26.9 \%)$ & $31(32.3 \%)$ & & \\
\hline \multirow[t]{2}{*}{ Direct admission/referral } & n (\%) & Direct admission & $89(68.5 \%)$ & $68(70.8 \%)$ & - & 0.770 \\
\hline & & Referral & $41(31.5 \%)$ & $28(29.2 \%)$ & & \\
\hline \multicolumn{7}{|l|}{ Clinical data } \\
\hline GCS score & \multicolumn{2}{|c|}{ Median (IQR) } & $14(9)$ & $13(8.5)$ & 1 & 0.608 \\
\hline $\mathrm{SBP}, \mathrm{mmHg}$ & \multicolumn{2}{|c|}{ Mean (SD) } & $108.5( \pm 32.0)$ & $104.9( \pm 29.9)$ & 1 & 0.482 \\
\hline \multicolumn{7}{|l|}{ Anatomical injury score } \\
\hline \multirow[t]{2}{*}{ ISS } & \multicolumn{2}{|c|}{ Median (IQR) } & $32.5(16)$ & $33(18)$ & - & 0.702 \\
\hline & \multicolumn{2}{|c|}{ Mean (SD) } & $32.9( \pm 11.4)$ & $33.6( \pm 12.1)$ & & \\
\hline \multirow[t]{2}{*}{ AIS head } & \multicolumn{2}{|c|}{ Median (IQR) } & $2(4)$ & $3(4.5)$ & - & 0.343 \\
\hline & \multicolumn{2}{|c|}{ Mean (SD) } & $2.2( \pm 2.1)$ & $2.4( \pm 2.0)$ & & \\
\hline \multirow[t]{2}{*}{ AIS face } & \multicolumn{2}{|c|}{ Median (IQR) } & $0(0)$ & $0(0)$ & - & 0.839 \\
\hline & \multicolumn{2}{|c|}{ Mean (SD) } & $0.51( \pm 1.0)$ & $0.44( \pm 0.9)$ & & \\
\hline \multirow[t]{2}{*}{ AIS chest } & \multicolumn{2}{|c|}{ Median (IQR) } & $3(4)$ & $3(3.5)$ & - & 0.777 \\
\hline & \multicolumn{2}{|c|}{ Mean (SD) } & $2.6( \pm 1.8)$ & $2.5( \pm 1.8)$ & & \\
\hline \multirow[t]{2}{*}{ AIS abdomen } & \multicolumn{2}{|c|}{ Median (IQR) } & $2(3)$ & $0(3)$ & - & 0.036 \\
\hline & \multicolumn{2}{|c|}{ Mean (SD) } & $1.83( \pm 1.7)$ & $1.36( \pm 1.7)$ & & \\
\hline \multirow[t]{2}{*}{ AIS pelvis and limbs } & \multicolumn{2}{|c|}{ Median (IQR) } & $3(3)$ & $3(1)$ & - & 0.138 \\
\hline & \multicolumn{2}{|c|}{ Mean (SD) } & $2.1( \pm 1.6)$ & $2.5( \pm 1.6)$ & & \\
\hline \multirow[t]{2}{*}{ AIS extremities } & \multicolumn{2}{|c|}{ Median (IQR) } & $0(1)$ & $0(0)$ & - & 0.05 \\
\hline & \multicolumn{2}{|c|}{ Mean (SD) } & $0.36( \pm 0.6)$ & $0.19( \pm 0.6)$ & & \\
\hline Laboratory data & & & & & & \\
\hline $\mathrm{pH}$ & Mean & & $7.32( \pm 0.1)$ & $7.29( \pm 0.1)$ & 56 & 0.398 \\
\hline Lactate mmol/L & Mean & & $3.15( \pm 1.7)$ & $3.18( \pm 2.7)$ & 52 & 0.094 \\
\hline $\mathrm{BE}$ & Mean & & $-4.47( \pm 3.5)$ & $-4.96( \pm 5.0)$ & 63 & 0.997 \\
\hline $\mathrm{Hb}, \mathrm{g} / \mathrm{dl}$ & Mean & & $10.8( \pm 2.4)$ & $11.2( \pm 2.1)$ & 13 & 0.240 \\
\hline PTL, $\mu l$ & Mean & & $196.6( \pm 70.9)$ & $205.3( \pm 77.4)$ & 53 & 0.439 \\
\hline INR & Mean & & $1.40( \pm 0.5)$ & $1.38( \pm 0.6)$ & 24 & 0.408 \\
\hline FIB (von Clauss method), mg/100 ml & Mean & & $184( \pm 92.8)$ & $196.0( \pm 85.4)$ & 69 & 0.276 \\
\hline
\end{tabular}

${ }^{a}$ AIS, Anatomical injury score; BE, Base excess; FIB EXTREMITIES, Fibrinogen; GCS, Glasgow Coma Scale; Hb, Hemoglobin; INR, International normalized ratio; IQR, Interquartile range; ISS, Injury Severity Score; PRBC, Packed red blood cells; PTL, Platelets; SBP, Systolic blood pressure; SD, Standard deviation.

The estimated costs of blood products are shown in Table 5. Compared with 2011, 2013 saw an overall 48\% reduction from $€ 326,818$ to $€ 170,220$, for a savings of $€ 156,598$. The additional cost of fibrinogen was $€ 53,600$. The cost for POC tests was $€ 26,663$ in 2013 compared with zero in 2011. However, these data also include the cost of tests performed for all bleeding patients in the OR and ICU, so POC test costs for study patients are overestimated. The average cost for blood components was $€ 2,528.80$ for each treated patient in the 2011 group versus $€ 1,492.60$ in 2013. Including charges for POC tests and fibrinogen, the average cost per patient in 2013 was $€ 2,322$, which is still $€ 206$ less than the average cost in 2011.

\section{Discussion}

The timely identification of patients who need aggressive hemostatic resuscitation remains challenging $[10,11]$. The ECS protocol is activated whenever significant uncontrolled bleeding is associated with one or more of the following criteria: SBP $<100 \mathrm{mmHg}, \mathrm{BE}$ less than -6 , lactate $>5 \mathrm{mmol} / \mathrm{L}$ and/or hemoglobin $<9 \mathrm{~g} / \mathrm{dl}$. These criteria were chosen by the TUN panel of experts based on data in the literature and on a retrospective analysis 
Table 3 Impact of introduction of early coagulation support protocol on consumption of blood components ${ }^{a}$

\begin{tabular}{|c|c|c|c|c|c|}
\hline & & 2011 & 2013 & Missing & $P$-value \\
\hline Patients with ISS $>15$ and $\geq 3 \mathrm{U}$ of PRBC & & 130 & 96 & & \\
\hline \multicolumn{6}{|l|}{ Blood components transfused within $24 \mathrm{hr}$} \\
\hline \multirow[t]{2}{*}{$\operatorname{PRBC}(U)$} & Mean (SD) & $8.09(6.7)$ & $6.5(4.8)$ & - & 0.149 \\
\hline & Median (IQR) & $5(6.0)$ & $4(5.5)$ & & \\
\hline \multirow[t]{2}{*}{ PTL (U) } & Mean (SD) & $4.18(5.9)$ & $2.68(4.75)$ & - & 0.046 \\
\hline & Median (IQR) & $0(6)$ & $0(6)$ & & \\
\hline \multirow[t]{2}{*}{ Plasma (U) } & Mean (SD) & $8.97(9.47)$ & $4.21(4.61)$ & - & $<0.001$ \\
\hline & Median (IQR) & $6(8)$ & $4(6)$ & & \\
\hline \multicolumn{6}{|l|}{ Outcome } \\
\hline Dead within $24 \mathrm{hr}$ & n (\%) & $8(6.15 \%)$ & $3(3.12 \%)$ & - & 0.361 \\
\hline Hospital mortality & n (\%) & $26(20.0 \%)$ & $13(13.5 \%)$ & - & 0.218 \\
\hline
\end{tabular}

${ }^{\mathrm{a}} \mathrm{QQR}$, Interquartile range; ISS, Injury Severity Score; PRBC, Packed red blood cells; PTL, Platelets; SD, Standard deviation.

of the TUN trauma registers [4]. Fibrinogen drops early in many patients who sustain a severe trauma, and low fibrinogen levels are associated with higher transfusion requirements and increased mortality [12]. Recently, Schlimp et al. [13] demonstrated that levels of fibrinogen $<150 \mathrm{mg} / \mathrm{dl}$ are detected in as many as $73 \%$ of patients with admission hemoglobin $<10 \mathrm{~g} / \mathrm{dl}$ and in $63 \%$ of those with a BE less than -6 . Moreover, Brohi and colleagues [14] found low fibrinogen in $41 \%$ of patients who were hypotensive on admission. Thus, the ECS criteria might well identify patients at high risk of hypofibrinogenemia. According to the ECS strategy, bleeding patients with evidence of severe hypoperfusion should receive a standard dose of $2 \mathrm{~g}$ of fibrinogen immediately. The decision to start coagulation support with fibrinogen before plasma infusion differs substantially from the standard clinical practice. In the Activation of Coagulation and Inflammation in Trauma (ACIT) study [15], cryoprecipitate was administered only after the first $6 \mathrm{U}$ of blood and after infusion of the first units of plasma. In the PRospective Observational Multicenter Major Trauma Transfusion (PROMMTT) study, the median time from admission to first cryoprecipitate unit administered was 2.7 hours [16]. In the ECS group, fibrinogen was always administered before plasma was started. A similar strategy is recommended in the Austrian guidelines [17]. However, the Austrian guidelines also recommend the early use of thromboelastometry to detect hypofibrinogenemia and guide treatment from the beginning. This strategy might not always be feasible at many Italian trauma centers, owing to a lack of resources and organizational limitations. Therefore, the ECS strategy supports the initial "blind" administration of fibrinogen to avoid any potentially dangerous delay. In the 2013 group, 50 (52\%) of 96 patients met the ECS criteria for an immediate dose of fibrinogen. These data are consistent with the Schöchl et al. study [18], in which $52 \%$ of patients qualified on the basis of viscoelastic tests and received their first dose of fibrinogen within 1 hour of admission. However, in contrast to the Schöchl et al. study the first dose of fibrinogen in our present study was administered to half of these patients, before the results of the basal ROTEM test were available and within 30 minutes of admission. Restoring or increasing fibrinogen levels may improve the clotting process, thus allowing a reduction in the amount of allogeneic blood components transfused. Plasma is currently used as a source of fibrinogen. However, although administration of plasma may stabilize fibrinogen levels and avoid a further decrease, plasma transfusions cannot produce a

Table 4 Changes in plasma-to-packed red blood cells ratio for each amount of packed red blood cells transfused before and after introduction of early coagulation support ${ }^{a}$

\begin{tabular}{|c|c|c|c|c|c|c|}
\hline Study year & & $3 U$ & 4 to $5 \mathrm{U}$ & 6 to $7 \mathrm{U}$ & 8 to $10 \mathrm{U}$ & $>10 \mathrm{U}$ \\
\hline \multirow[t]{3}{*}{2011} & Patients, n (\%) & $32(25 \%)$ & $39(30 \%)$ & $17(13 \%)$ & $10(7 \%)$ & $33(25 \%)$ \\
\hline & Average plasma units & 3.4 & 4.2 & 5.4 & 8.3 & 22.1 \\
\hline & Plasma:PRBC ratio & $1: 1$ & $1: 1$ & $0.8: 1$ & $1: 1$ & $1.2: 1$ \\
\hline \multirow[t]{3}{*}{2013} & Patients, n (\%) & $25(26 \%)$ & $33(34 \%)$ & $10(10 \%)$ & $12(13 \%)$ & $16(17 \%)$ \\
\hline & Average plasma units & 1.3 & 2.4 & 3.4 & 6.6 & 10.6 \\
\hline & Plasma:PRBC ratio & $1: 2.8$ & $1: 2$ & $1: 2$ & $0.8: 1$ & $0.7: 1$ \\
\hline
\end{tabular}

aPRBC, Packed red blood cells; PTL, Platelets. 
Table 5 Estimated cost for blood, blood components, factors and point-of-care tests over the two periods (2011 versus 2013)

\begin{tabular}{|c|c|c|c|c|c|c|}
\hline & & \multirow[t]{2}{*}{ Estimated cost for $1 \mathrm{U}$} & \multicolumn{2}{|l|}{2011} & \multicolumn{2}{|l|}{2013} \\
\hline & & & Units (N) & Overall & Units (N) & Overall \\
\hline PRBC & & $€ 186$ & 1,048 & $€ 194,928$ & 625 & $€ 116,250$ \\
\hline Plasma & & $€ 60$ & 1,167 & $€ 70,020$ & 405 & $€ 24,300$ \\
\hline \multirow[t]{3}{*}{ PTL } & & $€ 115$ & 538 & $€ 61,870$ & 258 & $€ 29,670$ \\
\hline & Overall & & & $€ 326,818$ & & $€ 170,220$ \\
\hline & Balance & & & & & $-€ 156,598$ \\
\hline Fibrinogen & & $€ 400(1 \mathrm{~g})$ & 0 & 0 & $134 \mathrm{~g}$ & $€ 53,600$ \\
\hline POC tests & & & 0 & 0 & & $€ 26,663$ \\
\hline \multirow[t]{2}{*}{ Overall } & & & 0 & 0 & & $+€ 80,263$ \\
\hline & Balance & & & & & $-€ 76,335$ \\
\hline
\end{tabular}

aPOC, Point of care; PRBC, Packed red blood cells; PTL, Platelets.

significant reversal of fibrinogenemia unless very high volumes are infused [19]. The ACIT study confirmed these findings [15].

In our study, the number of severe trauma patients (ISS $>15$ ) who received $\geq 3 \mathrm{U}$ of blood was $30 \%$ lower in 2013 than in 2011. This difference was independent of any change in the number of major trauma admissions to the two trauma centers and any change in the severity index of the admitted patients. In 2011, immediate administration of plasma to bleeding patients was the cornerstone of coagulation support. The plasma-toPRBC ratio in 2011 was approximately 1:1 for each amount of PRBC transfused (Table 4). Early and aggressive administration of plasma may result in diluting the blood cells with a decrease in hemoglobin level [20]. This may also reduce PTL marginalization with a potentially negative impact on PTL activation. Moreover, as 7 to $9 \mathrm{~g} / \mathrm{dl}$ hemoglobin was the transfusion trigger proposed in the 2010 European guidelines [5], the 2011 plasma-based strategy might have triggered a higher amount of blood transfusion, thus increasing the number of patients who received $\geq 3 \mathrm{U}$ of $\mathrm{PRBC}$. The data on plasma transfusion support this hypothesis. Among the patients transfused with $3 \mathrm{U}$ of blood, the percentage of those who received plasma decreased by more than half in 2013 compared with 2011 (27\% versus 56\%, respectively), and the average number of units of plasma used in 2013 was less than one-third that used in 2011 (1.2 versus 4.1, respectively). In 2013, the overall number of PRBC units was reduced by $40 \%$, plasma units by $65 \%$ and PTL by $52 \%$. Two different reasons are believed to have contributed to the observed decrease in the consumption of blood components: fewer patients who met the study criteria in 2011 compared with 2013 and a reduction in the average amount of PRBCs, plasma and PTL received by each one of the patients in the 2013 group. This difference was statistically significant for plasma and PTL. We observed a consistent reduction of the plasma-to-PRBC ratio for each amount of PRBC transfused (Figure 2). Data in the literature show that early and aggressive plasma transfusion improves the survival of trauma patients with critical bleeding [21-23]. However, availability of pre-thawed

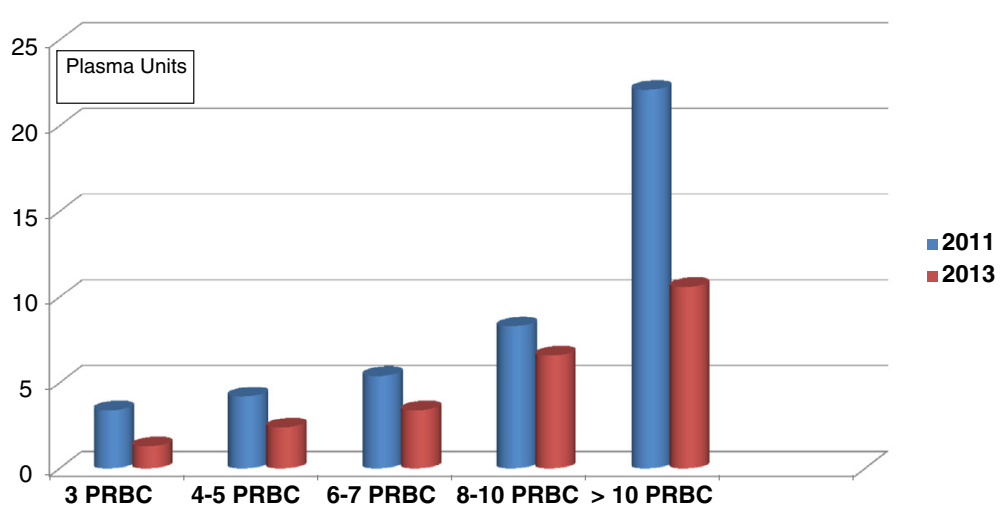

Figure 2 Changes in the number of plasma units transfused related to the amount of packed red blood cells before and after introduction of early coagulation support. PRBC, Units of packed red blood cells. 
plasma is not common in European trauma centers, making early plasma transfusion more a wish than a reality [24]. The average time to start plasma administration in the patients in our 2011 control group was 67 (8-90) minutes. Therefore, the administration of factors as recommended by the ECS protocol might significantly anticipate coagulation support. If fibrinogen concentrate is administered to increase fibrinogen level, there might be less need to transfuse plasma as a source of fibrinogen. Therefore, the lower plasma-to-PRBC ratio we observed in 2013 may be a consequence of the ECS strategy.

In our study, both early mortality and hospital mortality were lower in 2013 than in 2011 (3.12\% versus 6.15\% for early mortality and $13.5 \%$ versus $20.0 \%$ for hospital mortality, respectively). However, these are only preliminary data, and the study is not sufficiently powered to demonstrate statistically significant differences. The observed mortality compares favorably with the recent data from the PROMMTT study [25] (21.4\%), although the PROMMTT study included patients transfused with as little as $1 \mathrm{U}$ of PRBC and thus the average ISS was lower (26.4\%). Patients who undergo MT have a high mortality rate. Mortality rates ranging between 25\% [26] and 50\% [27-30] have been reported previously, with lower mortality for patients who received a high ratio of plasma to PRBC. MT patients in our study had a mortality rate ranging from $30 \%$ in 2011 to $25 \%$ in 2013. Patients in both groups received a high ratio of plasma to PRBC, although in 2011 they received twice as many plasma units as in 2013. This greatly reduced the economic costs of patient care, one of the key focal areas of our study. Görlinger et al. [31] demonstrated that goaldirected coagulation therapy based on POC monitoring, together with the use of factors, was associated with a sharp reduction in plasma and $\mathrm{PRBC}$ transfusions and a $€ 200,000$ decrease in the amount spent on blood products per year. Our findings indicate that the cost of blood and blood components was reduced by $48 \%$ in 2013 compared with 2011, for an estimated savings of more than $€ 150,000$ for the two study hospitals. Even taking into account the additional costs of fibrinogen and POC tests, there was still a savings of more than $€ 76,000$. Moreover, in Italy, there is a severe shortage of blood; therefore, saving blood and blood components has relevance independent of the economic impact.

Our study has several limitations. First, it is not a randomized controlled trial. Large, well-conducted studies with pragmatic endpoints are required to improve understanding of the complex interplay between bleeding and coagulopathy, transfusion requirements and mortality. However, these studies are extremely costly, which hinders their feasibility. For this reason, even the most recent recommendations for prevention and treatment of trauma coagulopathy could be based only on the results of observational studies. Our study shows that the introduction of a strategy based on ECS by means of factors administration, together with the use of viscoelastic POC and the ban of the use of colloids, was associated with a reduction in the need for blood and blood components. However, we were not able to define which of these contributed to the achievement of the results for each of the different components of the ECS strategy.

A restrictive fluid resuscitation protocol was used in both periods, although colloids were allowed in 2011 and not in 2013. The 2011 patients received $801( \pm 545)$ $\mathrm{ml}$ of 130.4 hydroxyethyl starch (HES) (Voluven; Fresenius Kabi, Bad Homburg, Germany) as an average. Gelatins were not used at all. HES may impair coagulation [32,33] and encourage bleeding, thus increasing the need for transfusion. Therefore, the choice to avoid colloids according to the 2013 ECS strategy might have had a relevant role in reducing iatrogenic coagulopathy.

In the ECS group, ROTEM was used to monitor coagulation. When POC is used, the finding of normal viscoelastic curves may support a more conservative approach to plasma transfusion [34]. The systematic use of thromboelastometry POC by the two trauma centers was introduced together with the ECS protocol as an integrated part of the same strategy. Therefore, the possibility to monitor coagulation by means of POC tests is a relevant difference between the 2011 and 2013 strategies. A sharp reduction in patient exposure to allogeneic blood products after the introduction of a thromboelastometryguided coagulation factor concentrate-based therapy has been reported previously by Schöchl et al. [35]. Therefore, on the basis of our results, we cannot state that the early administration of fibrinogen itself, if not associated with the other part of the strategy, is superior to the immediate administration of plasma, which is also recommended in the 2013 European guidelines. Despite the constraints of being an observational study, the results of the present study come from strictly controlled data, thanks to the existing electronic ICU records and blood bank databases. It must be stressed that the data presented here are just the preliminary results. For a better understanding of the impact of the ECS strategy, more data on morbidity (incidence of sepsis, acute respiratory distress syndrome, renal failure) and ICU and hospital lengths of stay are needed. The collection of these data is part of the study project. The analysis is ongoing and will be available within the next few months. The research study continues to involve more institutions, and it is hoped that the increasing numbers of patients included in the study will overcome some of the current limitations.

\section{Conclusions}

TUN recently developed a treatment protocol for bleeding trauma patients called early coagulation support. 
The ECS protocol must be considered as part of a comprehensive damage resuscitation control strategy. The introduction of the ECS protocol in two Italian trauma centers was associated with a marked reduction in blood product consumption, reaching statistical significance for plasma and PTL, and with a non-significant trend toward a reduction in early and 28-day mortality. The overall costs of transfusion and coagulation support (including POC tests) decreased by $23 \%$. These data need to be confirmed with an adequate number of patients. This is the aim of a larger, ongoing multicenter study.

\section{Key messages}

- In every hospital, there is a need for protocols for managing critical bleeding and prevention of coagulopathy.

- The use of the early coagulation support protocol developed by the Italian Trauma Centers Network was associated with a marked reduction in the consumption of blood and blood components, with an associated cost saving.

- There is a strong need for controlled trials to confirm these data.

\begin{abstract}
Abbreviations
ACIT: Activation of Coagulation and Inflammation in Trauma study; AIS: Anatomical injury score; aPTT: Activated partial thromboplastin time; BE: Base excess; ECS: Early coagulation support; FIB: Fibrinogen; GCS: Glasgow Coma Scale; Hb: Hemoglobin; HES: Hydroxyethyl starch; ICU: Intensive care unit; INR: International normalized ratio; IQR: Interquartile range; ISS: Injury Severity Score; MT: Massive transfusion; OR: Operating room; POC: Point of care; PRBC: Packed red blood cells; PROMMTT: PRospective Observational Multicenter Major Trauma Transfusion study; PT: Prothrombin time; PTL: Platelets; ROTEM: Rotational thromboelastometry; SBP: Systolic blood pressure; SD: Standard deviation; TBI: Traumatic brain injury; TUN: Italian Trauma Centers Network.
\end{abstract}

\section{Competing interests}

GN is a member of the Task Force for Advanced Bleeding Care in Trauma (ABC-T), whose objective is to develop and update the European guidelines on management of bleeding following major trauma. The ABC-T meetings are supported by an unrestricted grant from CSL Behring (in the past by Novo Nordisk). In the past 5 years, GN has received honoraria and travel funding to participate in the ABC-T meetings. GN has also received honoraria from CSL Behring for lecturing. All of the other authors declare that they have no competing interests.

\section{Authors' contributions}

GN made a substantial contribution in promoting the protocol and planning the study. He also contributed to conception and drafting of the manuscript. VA substantially contributed to the conception of the study design, reviewed the literature and contributed to drafting the manuscript. She critically revised the scientific content of the manuscript. BR was responsible for blood bank data collection at the Rome site. She also reviewed the literature and contributed to manuscript drafting and revision. ER was responsible for the statistical analysis. He critically revised the manuscript. BB was responsible for ICU data collection at the Rome site. She critically revised the manuscript. GB was responsible for ICU data collection at the Cesena site and helped to draft the manuscript. SB was involved in blood bank data collection at the Cesena site and was involved in the statistical analysis. EC was involved in ICU data collection at the Rome site. He critically revised the manuscript. AD was involved in ICU data collection at the Rome site. He helped to revise the manuscript. GG critically revised the manuscript and the statistical analysis. GR was involved in the study planning and data collection. All authors read and approved the final manuscript and agree to be accountable for all aspects of the work.

\section{Author details}

${ }^{1}$ Department of Shock and Trauma Center, S Camillo-Forlanini Hospital, Circonvallazione Gianicolense 87, Roma 00152, Italy. ${ }^{2}$ Departement of Clinical Pathology and Transfusion Medicine, Bufalini Hospital, Via Ghirotti 286, Cesena 45072, Italy. ${ }^{3}$ Department of Hematology and Transfusion Medicine, S Camillo-Forlanini Hospital, Circonvallazione Gianicolense 87, Roma 00152, Italy. ${ }^{4}$ Department of Anesthesia and ICU, Trauma Service, Bufalini Hospital, Via Ghirotti 286, Cesena 45072, Italy. ${ }^{5}$ Department of Anesthesia and Intensive Care, University of Siena, Strada delle Scotte 14, Siena 53100, Italy.

Received: 8 October 2014 Accepted: 17 February 2015

Published online: 12 March 2015

References

1. Brohi K, Singh J, Heron M, Coats T. Acute traumatic coagulopathy. J Trauma. 2003:54:1127-30.

2. Rossaint R, Bouillon B, Cerny V, Coats TJ, Duranteau J, Fernández-Mondéjar E, et al. The STOP the bleeding campaign. Crit Care. 2013;17:136.

3. Spahn DR, Bouillon B, Cerny V, Coats TJ, Duranteau J, Fernández-Mondéjar $E$, et al. Management of bleeding and coagulopathy following major trauma: an updated European guideline. Crit Care. 2013;17:R76.

4. Nardi G, Agostini V, Rondinelli MB, Bocci G, Di Bartolomeo S, Bini G, et al. Prevention and treatment of trauma induced coagulopathy (TIC): an intended protocol from the Italian Trauma update research group. J Anesthesiol Clin Sci 2013;2:22. doi:10.7243/2049-9752-2-22. www. hoajonline.com/jacs/2049-9752/2/22. Accessed 14 Mar 2015

5. Rossaint R, Bouillon B, Cerny V, Coats TJ, Duranteau J, Fernández-Mondéjar E, et al. Management of bleeding following major trauma: an updated European quideline. Crit Care. 2010;14:R52

6. Holcomb JB, Jenkins D, Rhee P, Johannigman J, Mahoney P, Mehta S, et al. Damage control resuscitation: directly addressing the early coagulopathy of trauma. J Trauma. 2007;62:307-10.

7. CRASH-2 trial collaborators: Shakur H, Roberts I, Bautista R, Caballero J, Coats $T$, Dewan $Y$, et al. Effects of tranexamic acid on death, vascular occlusive events, and blood transfusion in trauma patients with significant haemorrhage (CRASH-2): a randomised, placebo-controlled trial. Lancet. 2010;376:23-32.

8. Giunta Regionale della Regione Emilia Romagna. Ridefinizione delle tariffe relative alla cessione di sangue ed emoderivati fra le Strutture Sanitarie Pubbliche e Private. GPG/2010/1816. 8 Nov 2010.

9. Ruscitti G Tutti i costi delle trasfusioni (all transfusion-related costs) II Sole 24 Ore Sanità, 7 Jul 2008.

10. Brockamp T, Nienaber U, Mutschler M, Wafaisade A, Peiniger S, Lefering R, et al. Predicting on-going hemorrhage and transfusion requirement after severe trauma: a validation of six scoring systems and algorithms on the TraumaRegister DGU. Crit Care. 2012;16:R129. doi:10.1186/cc11432.

11. Maegele M, Brockamp T, Nienaber U, Probst C, Schoechl H, Görlinger K, et al. Predictive models and algorithms for the need of transfusion including massive transfusion in severely injured patients. Transfus Med Hemother. 2012;39:85-97.

12. Inaba K, Karamanos E, Lustenberger T, Schöchl H, Shulman I, Nelson J, et al. Impact of fibrinogen levels on outcomes after acute injury in patients requiring a massive transfusion. J Am Coll Surg. 2013;216:290-7.

13. Schlimp CJ, Voelckel W, Inaba K, Maegele M, Ponschab M, Schöchl H. Estimation of plasma fibrinogen levels based on hemoglobin, base excess and ISS upon emergency room admission. Crit Care. 2013;17:R137.

14. Rourke C, Curry N, Khan S, Taylor R, Raza I, Davenport R, et al. Fibrinogen levels during trauma hemorrhage, response to replacement therapy and association with patient outcomes. J Thromb Haemost. 2012;10:1342-51.

15. Khan S, Brohi K, Chana M, Raza I, Stanworth S, Gaarder C, et al. Hemostatic resuscitation is neither hemostatic nor resuscitative in trauma hemorrhage. J Trauma Acute Care Surg. 2014;76:561-8.

16. Holcomb JB, Fox EE, Zhang X, White N, Wade CE, Cotton BA, et al. Cryoprecipitate use in the PROMMTT study. J Trauma Acute Care Surg. 2013;75:S31-9.

17. Fries $D$, Innerhofer $P$, Perger $P$, Gütl M, Heil S, Hofmann N, et al. Coagulation management in trauma-related massive bleeding: recommendations of the Task Force for Coagulation (AGPG) of the Austrian Society of 
Anesthesiology, Resuscitation and Intensive Care Medicine (OGARI). Anasthesiol Intensivmed Notfallmed Schmerzther. 2010;45:552-61. doi:10.1055/s-0030-1265746. German.

18. Schöchl H, Nienaber U, Hofer G, Voelckel W, Jambor C, Scharbert G, et al. Goal-directed coagulation management of major trauma patients using thromboelastometry (ROTEM)-guided administration of fibrinogen concentrate and prothrombin complex concentrate. Crit Care. 2010;14:R55.

19. Chowdary P, Saayman AG, Paulus U, Findlay GP, Collins PW. Efficacy of standard dose and $30 \mathrm{ml} / \mathrm{kg}$ fresh frozen plasma in correcting laboratory parameters of haemostasis in critically ill patients. Br J Haematol. 2004;125:69-73.

20. Hess JR. Resuscitation of trauma-induced coagulopathy. Hematology Am Soc Hematol Educ Program. 2013;2013:664-7. doi:10.1182/asheducation-2013.1.664.

21. Stinger HK, Spinella PC, Perkins JG, Grathwohl KW, Salinas J, Martini WZ, et al. The ratio of fibrinogen to red cells transfused affects survival in casualties receiving massive transfusions at an army combat support hospital. J Trauma. 2008;64:S79-85.

22. Borgman MA, Spinella PC, Holcomb JB, Blackbourne LH, Wade CE, Lefering $R$, et al. The effect of FFP:RBC ratio on morbidity and mortality in trauma patients based on transfusion prediction score. Vox Sang. 2011;101:44-54.

23. Ho AM, Dion PW, Yeung JH, Holcomb JB, Critchley LA, Ng CS, et al. Prevalence of survivor bias in observational studies on fresh frozen plasma:erythrocyte ratios in trauma requiring massive transfusion. Anesthesiology. 2012;116:716-28.

24. Snyder CW, Weinberg JA, McGwin Jr G, Melton SM, George RL, Reiff DA, et al. The relationship of blood product ratio to mortality: survival benefit or survival bias? J Trauma. 2009;66:358-64.

25. Cohen MJ, Kutcher M, Redick B, Nelson M, Call M, Knudson MM, et al. Clinical and mechanistic drivers of acute traumatic coagulopathy. J Trauma Acute Care Surg. 2013;75:S40-7.

26. Maegele M, Lefering R, Paffrath $T$, Tjardes T, Simanski C, Bouillon B, the Working Group on Polytrauma of the German Society of Trauma Surgery (DGU). Red blood cell to plasma ratios transfused during massive transfusion are associated with mortality in severe multiply injury: a retrospective analysis from the Trauma Registry of the Deuthche Gesellschaft für Unfallschirurie. Vox Sang. 2008;95:112-9.

27. Johansson PI, Stensballe J. Hemostatic resuscitation for massive bleeding: the paradigm of plasma and platelets - a review of the current literature. Transfusion. 2010:50:701-10.

28. Cotton BA, Gunter OL, Isbell J, Au BK, Robertson AM, Morris Jr JA, et al. Damage control hematology: the impact of a trauma exsanguination protocol on survival and blood product utilization. J Trauma. 2008;64:1177-83.

29. Gunter Jr OL, Au BK, Isbell JM, Mowery NT, Young PP, Cotton BA. Optimizing outcomes in damage control resuscitation: identifying blood product ratios associated with improved survival. J Trauma. 2008;65:527-34

30. Magnotti $L$, Zarzaur BL, Fischer PE, Williams RF, Myers AL, Bradburn EH, et al. Improved survival after hemostatic resuscitation: does the emperor have no clothes? J Trauma. 2011;70:97-102.

31. Görlinger K, Fries D, Dikmann D, Weber CF, Hanke AA, Schöchl H. Reduction of fresh frozen plasma requirements by perioperative point-of care coagulation management with early calculated goal-directed therapy. Transfus Med Hemother. 2012;39:104-13.

32. Myburgh JA, Finfer S, Bellomo R, Billot L, Cass A, Gattas D, et al. Hydroxyethyl starch or saline for fluid resuscitation in intensive care. N Engl J Med. 2012;367:1901-11.

33. Winstedt D, Thomas OD, Nilsson F, Olanders K, Schött U. Correction of hypothermic and dilutional coagulopathy with concentrates of fibrinogen and factor XIII: an in vitro study with ROTEM. Scand J Trauma Resusc Emerg Med. 2014:22:73. doi:10.1186/s13049-014-0073-z.

34. Haas T, Görlinger K, Grassetto A, Agostini V, Simioni P, Nardi G, et al. Thromboelastometry for guiding bleeding management of the critically ill patient: a systematic review of the literature. Minerva Anestesiol. 2014;80:1320-35.

35. Schöchl H, Nienaber U, Maegele M, Hochleitner G, Primavesi F, Steitz B, et al. Transfusion in trauma: thromboelastometry-guided coagulation factor concentrate-based therapy versus standard fresh frozen plasma-based therapy. Crit Care. 2011;15:R83.

\section{Submit your next manuscript to BioMed Central and take full advantage of:}

- Convenient online submission

- Thorough peer review

- No space constraints or color figure charges

- Immediate publication on acceptance

- Inclusion in PubMed, CAS, Scopus and Google Scholar

- Research which is freely available for redistribution

Submit your manuscript at www.biomedcentral.com/submit 